\title{
Challenges of Nurse Tutors' Classroom and Clinical Performance When Teaching
}

\author{
Noel D. Mbirimtengerenji1 ${ }^{1}$, Felicity Daniels ${ }^{2}$, Penelope Martin'2 \\ ${ }^{1}$ Kamuzu College of Nursing, University of Malawi, Lilongwe, Malawi \\ ${ }^{2}$ University of Western Cape, Bellville, South Africa \\ Email: ndmbiri@kcn.unima.mw, fdaniels@uwc.ac.za, pmartin@uwc.ac.za
}

Received 9 June 2015; accepted 14 August 2015; published 17 August 2015

Copyright (C) 2015 by authors and Scientific Research Publishing Inc.

This work is licensed under the Creative Commons Attribution International License (CC BY). http://creativecommons.org/licenses/by/4.0/

(c) $\underset{\mathrm{EY}}{\mathrm{BY}}$ Open Access

\begin{abstract}
Introduction: Nursing is a dual profession that involves teaching both in class and at the clinical area. Nurse tutors meet a lot of challenges in their profession through their cognitive, affective and psychomotor nursing performance. The aim of this paper is to determine the challenges of nurse tutor clinical affective, cognitive and psychomotor performance in Malawi. Methods: Mixed methods design was employed. Quantitatively, 129 students and 82 nurse tutors randomly selected were involved for the five ranked Likert Scale questionnaire, and 42 nurse tutors were involved in in-depth. While 8 focus group discussions were conducted in 8 nursing colleges. Descriptive and inferential statistics were used quantitatively for predictive variable of nurse tutor work experience and student study experience to compare with the dependent variables from the 39 cognitive, affective and psychomotor attributes. Results: Both nurse tutors and students are not impressed with nurse tutors cognitive, affective and psychomotor performance during teaching. There is inadequate clinical orientation to students [OR $\leq 0.302 ; 95 \% \mathrm{CI}(0.096 \pm 2.955) ; \mathrm{p} \geq 0.042]$ and inadequate funding from college administration [OR $\leq 1.013 ; 95 \% \mathrm{CI}(0.271 \pm 3.793) ; \mathrm{p} \geq 0.985]$ as a result it creates much pressure on teaching. Conclusion: There is a need to develop an effective teaching strategy that would be conducive and easy to use for the limited resource environments in Malawi.
\end{abstract}

\section{Keywords}

Nurse Tutor Challenges, Nurse Tutor Performance, Nurse Tutor Work Experience, Student Study Experience

\section{Introduction}

Clinical skills underpin nurses’ professional practice and thus nurse tutors need effective opportunities to ac- 
quire, develop and master these skills [1]. Enabling practical skills development is a key dimension of nursing education [2]. It is stated that nurse tutors are charged with the responsibility of creating a learning environment and learning opportunities that are inviting, challenging and motivating, and that promote critical thinking and problem-solving skills to students. This is because nursing education must be both formal and informal that utilizes different teaching strategies both in class and at the clinical area.

Since nursing is a dual profession that involves teaching both in class and at the clinical area, Nurse tutors meet a lot of challenges in their profession through their cognitive, affective and psychomotor nursing performance. There must be much effort done by nurse tutors to let the students acquire these learning domains from different clinical settings as the tutors are perceived as role models in teaching. This challenges nurse tutors in ensuring that the integration of theory and clinical practice occurs basing on their cognitive, affective and psychomotor performance.

The integration of knowledge, skills, attitudes and values in a specified context is one of the cornerstones advocated by the outcomes-based approach to teaching nursing [3]. Such integration yields nurse tutor performance that must promote the professional care to patients. However, there have been increased challenges to the level of these performances of the nurse tutors in the clinical area in Malawi. Clinical performance of the nursing students depends upon the ward sisters and the nurse educator [4]. Clinical teaching is one of the core components of the role of the nurse tutors. Most of the clinical teaching of nursing students is done by nurse educators. However, there is no clear literature that has evaluated the clinical performance of the nurse tutors in Malawi basing on the cognitive, affective and psychomotor domains.

The philosophy of clinical instructions provides a framework for making curricular choices from among options and understanding the implications of alternate educational decisions, values and beliefs that provide structure and coherence for a curriculum [5]. Without structured instructions, the performance of the nurse tutor cannot be qualitative.

The way in which performance in nursing and midwifery is managed and measured is of concern to individual practitioners, managers, employing organizations, nursing educators and to patients. Most nurses and other health care practitioners in Malawi do not measure cognitive, affective and psychomotor nurse tutor performance correctly. By definition, performance is a reference to the nursing knowledge, skill or judgment possessed and applied by the nurse and/or midwife in the practice of the nursing and/or midwifery [6]. Cognitive performance focuses on the professional knowledge level of the nurse tutor when discharging duties in the clinical area. In this study, the professional cognitive performance of a nurse and/or midwife is unsatisfactory if it is below the standard reasonably expected of a nurse and/or midwife of an equivalent level of training or experience. The professional affective performance of the nurse tutor describes the professional attitudes that she or he discharges during teaching to nursing students in the clinical area while the professional psychomotor performance of the nurse tutor characterises the attributes of the nurse tutor that deals with the action oriented skills in the clinical area.

The fact that nurses spend more time with patients than do any other health care providers, patient outcomes are affected by nursing cognitive, affective and psychomotor quality care. This helps to give nurses much emphasis on determining the level of such performance during. Thus, improvements in patient safety can be achieved by improving nurse tutor performance attributes in clinical teaching to students. Another author [7] reviewed literature on nursing performance, which included cognitive, physical, and organizational factors that affected performance. It is noted that nurse's work system often does not accommodate human limits and capabilities and that nurses work under cognitive, perceptual, and physical overloads which in turn, impinge clinical performance. Specifically, nurses engage in multiple tasks under cognitive load.

Matching teaching and learning to students is often not possible hence the notion that educators have to adopt a variety of teaching styles to accommodate a variety of learning styles [8]. Diversity in the use of teaching styles is crucial for the attainment of cross-cutting core competencies and achieves better performance in nursing in the clinical area.

It is important for teachers to realize that learners in nursing are adult learners and, according to Knowles's theory. They possess the characteristics of self-concept with plenty of experience to connect new knowledge for meaningful understanding and interpretation of thoughts and feelings. Literature has also pointed out the concerns about the lack of skills and experience of some nurse tutors, and suggested that this can contribute to the poor performance of nursing students. They claim that some tutors are not specialized enough in their fields of knowledge, and that results in a drop in learners' motivational levels [5]. 
The quality of some nurse tutors performance is equal to that of the ward sisters who are not specialized in their field. On the other hand, tutor participants voice their needs to management to specialize in different fields, but there is limited support from management [9]. Nurse tutors complain that they do not get any study leave or long leave and cannot even attend developmental professional course which mostly demotivates them.

Moreover, several recent high profile cases of poor nurse tutor practice in nursing have been documented in Malawi [10]. Individual and institutional have highlighted the importance of managing and learning from poor performance. Scholars have recently defined poor performance as: "any aspects of a practitioner's conduct which: pose a threat or potential threat to patient safety; expose services to financial or other substantial risk; undermine the reputation or efficiency of services in some significant way; and are outside acceptable practice guidelines and standards". However, this definition has yet to be evaluated against practice and the extent to which it proves to be a robust and shared definition of poor performance among nurse tutors, necessary to assess, best manage and improve practice is yet unknown in Malawi. Whilst current global guidelines define poor performance primarily in relation to patient safety and risk, in nursing practice, more than $20 \%$ of nurses are suspended for professional incompetency reasons in nursing education [11].

Tutors have access to a mix of courses to improve teaching psychomotor skills and knowledge. Registered nurses with generic nursing degrees have access to scholarships to upgrade their qualifications in Malawi. For example, Kamuzu College of Nursing (KCN) has been training nurse tutors at degree level mature entry for more than 15 years. In this programme, experience registered nurses are selected from different hospitals and attend to a two year Bachelor of Science degree in nursing education. Some courses that they learn are the teaching strategies in nursing; curriculum development, curriculum administration and teaching practicum as the skill acquisition process in readiness to their tutorship deployment in the country' nursing colleges. KCN also developed a short course in teaching methodology for assistant tutors and clinical instructors from CHAM institutions [12]. Therefore, a reasonable number of the qualified nurse tutors with a degree are deployed into the nursing schools [13]. There has not been any study that evaluates the cognitive, affective and psychomotor clinical performance of these nurse tutors. To this effect, the aim of this paper is to determine the challenges of nurse tutor clinical cognitive, affective, and psychomotor performance in Malawi. This study is an eye opener to both nursing administrators and nurse educators on the improvement of the classroom and clinical cognitive, affective and psychomotor performance during teaching.

\section{Methodology}

The study design for this research was descriptive exploratory mixed methods which utilized both qualitative and sequential quantitative methods. This research was conducted in Malawi from CHAM nursing Colleges. There were 158 tutors and 2075 students in all the CHAM nursing colleges by 2013.

Iterated purposive, Sampling (IPPS) frame for nurse tutor performance was used. In order to achieve a sample worthy generalization quantitatively, the sample were drawn from the colleges basing on approximated (random probability) number of tutors and students respectively. Drawing sample from the population was initiated until the desired sample was achieved and used the following sample proportion formula: Sample Size = $n /[1+(n /$ population $)]$ BUT $n=Z^{2} P(1-P) / E^{2}$ Where $n$ is sample size of tutors and students in colleges, $P$ is the proportion of number of tutors or students and $E$ is the margin error [14]. This formula allowed $5 \%$ for expected margin of error $(E)$ with $95 \%$ confidence level as the denominator. $Z^{2}$ was a constant score with a value of $1.96^{2}$ (at $95 \%$ confidence level and 5\% precision [14]. So, this suggest that 129 students and 82 nurse tutors iterated randomly selected, participated in the performance study. Moreover, 42 nurse tutor squalitatively, four from each college, were purposively selected for in-depth interviews on the cognitive and psychomotor performance attributes. Furthermore, 10 students in one focus group discussion for each nursing college were also involved qualitatively.

As inclusion criteria, only two or more years of work experienced nurse tutors participated particularly on cognitive and affective performance attributes in Focus Group and In-Depth Interviews. Only those tutors that had undergone the teaching methodology training participated for the two questionnaires of nurse tutor questionnaire and student questionnaire. Only those students that have been in class for more than one year as their study experience participated in the study.

There were three main instruments used for this study; two structured questionnaires; the In-depth interview (IDI) and Focus Group Discussion (FGD) that articulated the affective and cognitive performance of the nurse 
tutors. The three instruments were administered concurrently to intensify the construct and face validity and reduce recall bias. 39 cognitive, affective and psychomotor performance attributes were classified and levelled in a five ranked Likert scale questionnaire.

The collected quantitative data were entered on SPSS software version 20.0 and the qualitative data was stored in ATLAS-ti 7.0. Descriptive statistics in the form of frequencies, bivariate analysis and binary logistic regression basing on the cognitive, affective and psychomotor performance attributes were computed for tutors' for all the 38 performance attributes against the predictor variables of nurse tutor work experience and student study experience in different nursing colleges.

The research used bivariate spearman correlation coefficient and binary logistic regression. Nurse tutor work experience and student study experience were used as independent and predictor variables against different nurse tutor performance variables as dependent variables. This was done to generate relationship tables, correlation tables from bivariate analysis and binary logistic regression tables. Only variables that showed correlation in the bivariate analysis were used in the binary logistic regression models to deduce the odds ratio, confidence interval and the beta coefficient results

This research used four criteria for establishing the trustworthiness of qualitative data from the tutors, students and administrators: These were credibility, dependability, confirmability, and transferability. Bias was reduced by doing face to face interview during data collection to iterated randomized nurse tutors and students [15]. Categorizing the participants into three different strata of tutors, student and administrators also helped to reduce bias. Use of limited time on data collection also assisted to reduce bias in the study. The inferential data analysis that focused on bivariate and binary logistic regression helped to reduce bias and control confounding [14]. The content validity for the instruments in the study was maintained by requesting opinions of the experts from two international universities; thus, University of Malawi, and University of Western Cape.

The internal consistency was measured with Cronbach's alpha as the performance attributes were more than 30 in the five ranked Likert scale [16] and variation of alpha values was determined in each item. This was so as Cronbach's alpha is an index of reliability associated with the variation accounted by the true score of the "underlying variables [17].

There were five ways on how this study controlled confounding variables. The most important methods that were used were randomization, restriction, matching, stratification and inferential analysis [14]. This study had an approval from ethical review boards from, University of Western Cape (UWC) and from University of Malawi (UNIMA) through COMREC. All nursing tutors' and students' participants were assured that no form of human rights violation would be encountered in the due course of the nationwide nursing tutor-student clinical performance following the 1964 Declaration of Helsinki; [14] [18] the 1978 Belmont Report; Baltimore Treaty on Ethical Codes (BTEC) and the Nuremburg Codes in medical education research.

\section{Results}

Nurse tutor performance when teaching in the clinical area were analysed using the tutors' perspective and the students' perspective in a five ranked Likert scale. There were 39 different cognitive, affective and psychomotor performance items that focus on nurse tutors. The Cronbach's alpha which is the reliability statistics was measured and the outcome from the SPSS was 0.954. Generally both nurse tutors and students are not impressed with nurse tutors performance during teaching. This is also the same to nurse tutors and students who clearly indicated dissatisfaction with the nurse tutors' cognitive, affective and psychomotor performance at the clinical area.

In Figure 1, the affective performance of nurse tutors on care of student social support at the clinical area was analysed. 21\% (27) $n=129$ of the students from Trinity Nursing College and St. Johns Nursing College agreed that nurse tutors have sense of care during teaching nursing procedures to students. While $19 \%$ (24) $n=$ 129 of the students from Ekwendeni Nursing College agreed that their nurse tutors have sense of support and care during teaching both in class and at the clinical area. It was Mulanje nursing College that had the least of the number of students that agreed that their nurse tutors have sense of support and care during teaching both in class and at the clinical area.

Figure 2 illustrates the distribution of students on how they perceive their tutors show interest in clinical learning. 65\% (13) $n=20$ of the students from St. Johns Nursing College strongly agreed that their nurse tutors effectively show interest in clinical learning of the students when teaching. This was followed by Trinity Nursing College where the data illustrates that $54.5 \%$ (12) $n=22$ of the students agreed that their nurse tutors show 


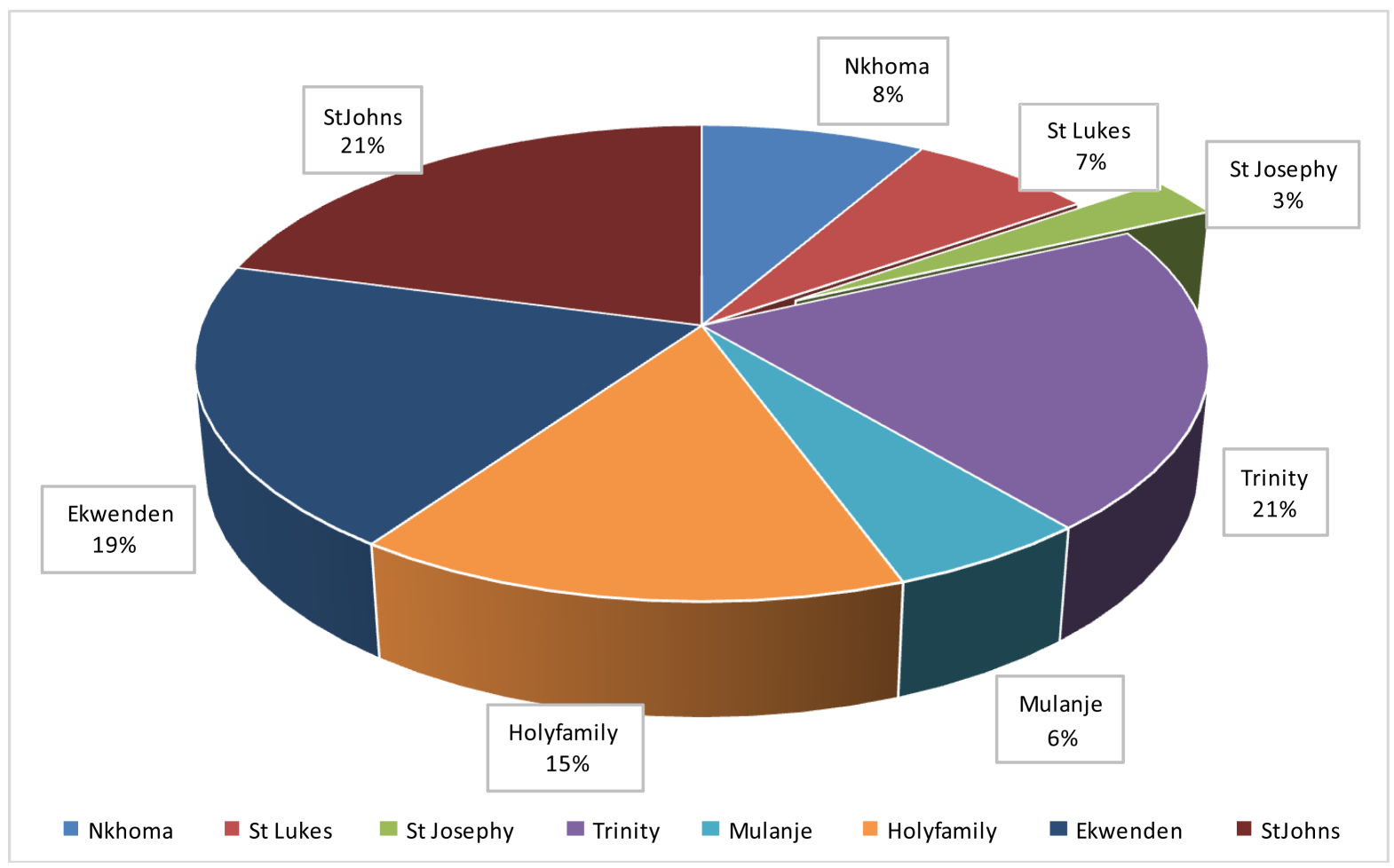

Figure 1. Distribution of students on those that agreed that tutors have sense of care and social support.

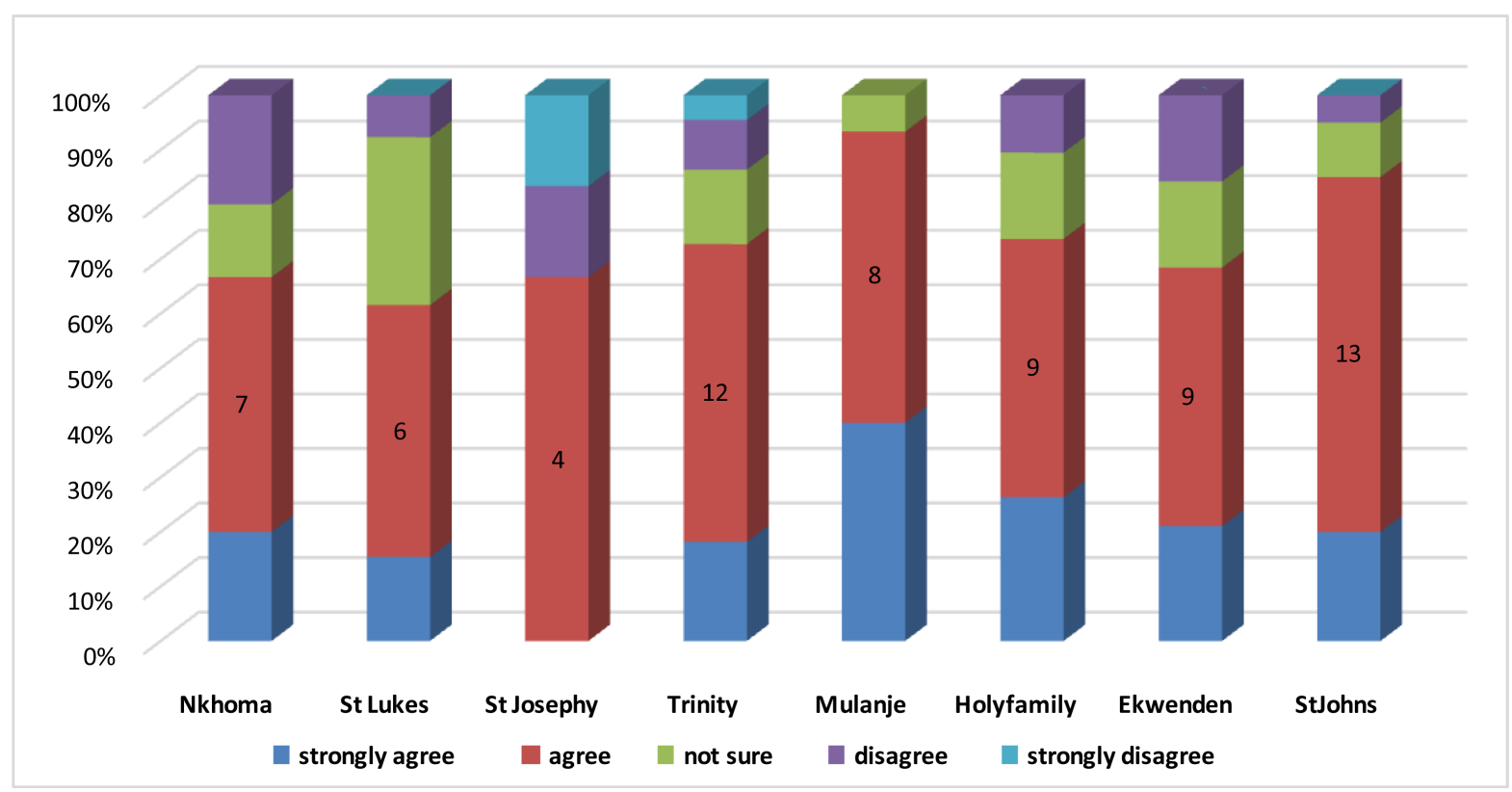

Figure 2. Students distribution on how their tutors show interest in clinical learning.

interest in clinical learning of the students. Holy Family nursing College and Ekwendeni Nursing College also showed high number of students who agreed that their nurse tutors show interest in clinical learning of the students. However, 48.4\% (6) $n=13$ of the students from St. Lukes nursing College were not sure whether their nurse tutors show interest in clinical learning of the students. This is very pathetic as it shows that students were afraid to say the truth about their nurse tutors affective performance on clinical learning of the students. But in general, $52.7 \%$ (68) $n=129$ of the students from all nursing colleges agreed that they show interest on clinical student 
learning. This entails that affective performance of students on student clinical learning is very low. This is because clinical learning of the students is paramount to quality nurses in the country. However, some nurse tutors were very defensive on the affective and psychomotor Performance in class. For example a nurse tutor in St. Lukes Nursing College pointed that:

Am found where am supposed to be found, if am supposed to be in class am in class unless there are very tentative reasons, if am supposed to be at the clinical area, am at the clinical area unless there are very uncontrollable reasons and when am in class am supposed to teach I go there to teach and when am in the clinical area I go there to supervise, demonstrate and I also make sure I do what am supposed to do.

In Figure 3, the psychomotor performance of nurse tutors on demonstration of clinical procedures were also assessed to the students. In Trinity nursing college $68.1 \%$ (15) $n=22$ of the students agreed that their tutors effectively demonstrates on clinical procedures during teaching. Almost all students from Mulanje Nursing College agreed that their nurse tutors demonstrate effectively on clinical procedures during teaching particularly in the clinical area. However, 73\% (14) $n=19$ of the students from Ekwendeni Nursing College also agreed that their nurse tutors perform effectively during demonstration of clinical procedures particularly at the clinical area. Generally, only 54.3\% (70) $n=129$ of the students from all the nursing colleges agreed that their nurse tutors effectively demonstrates clinical procedures both in class and art the clinical area. However, most of the nurse tutors complained that due to critical scarcity of the equipment, improvisation has remained a remedy during demonstration that reduces quality of the procedures during teaching.

The teaching cognitive and affective performance of the nursing tutors on gender sensitivity during teaching in the clinical area was also analysed in both the students and nurse tutors. $68 \%(15) n=22$ of the students from Trinity Nursing College agreed that nurse tutors are gender sensitive during teaching (see Figure 4). But some students explained that the main challenge of the nurse tutors is limited availability in the clinical area as a result they do not discharge their clinical skills frequently to students.

$52.6 \%$ (10) $n=19$ of the students from Holy Family nursing college also agreed that their nurse tutors are gender sensitive when teaching both in class and at the clinical area. However, 58.1\% (75) $n=129$ of the students agreed that nurse tutors are gender sensitive and understand the gender roles and sexual differences of the students. But one of the male nurse tutors pointed out that the main challenge is that nursing profession is female dominated, therefore, male nurses feel inferior at times to too many female faculty staff in the colleges.

In Table 1, the psychomotor performance of the nurse tutors in clinical area was also assessed particularly on the ability to act as a guide as opposed to dominating the group during teaching. 43.7\% (7) $n=16$ of the nurse tutors in Nkhoma Nursing school agreed that they have ability to act as a guide as opposed to dominating the

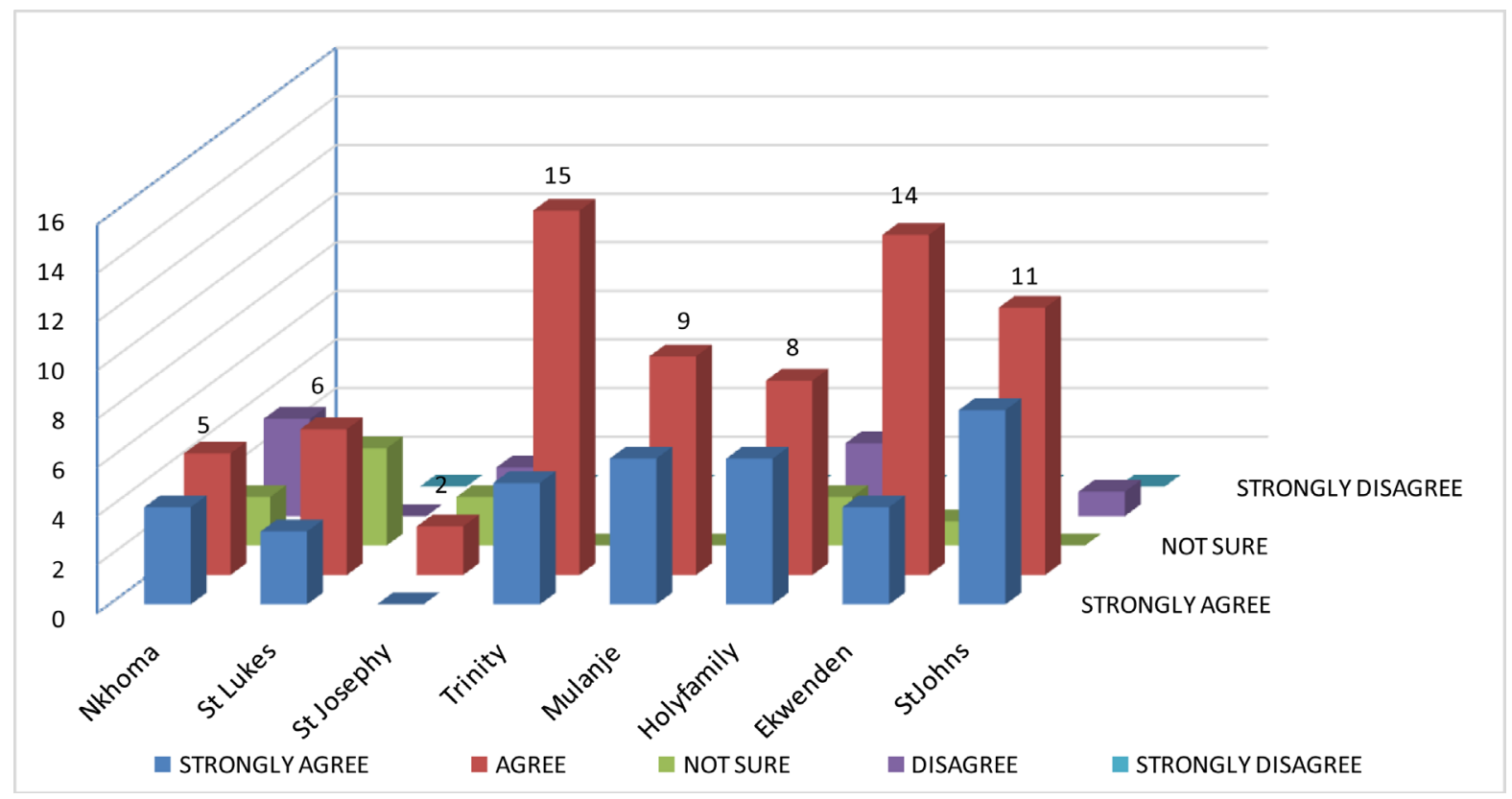

Figure 3. Students distribution on how their tutors effectively demonstrate on clinical procedures. 


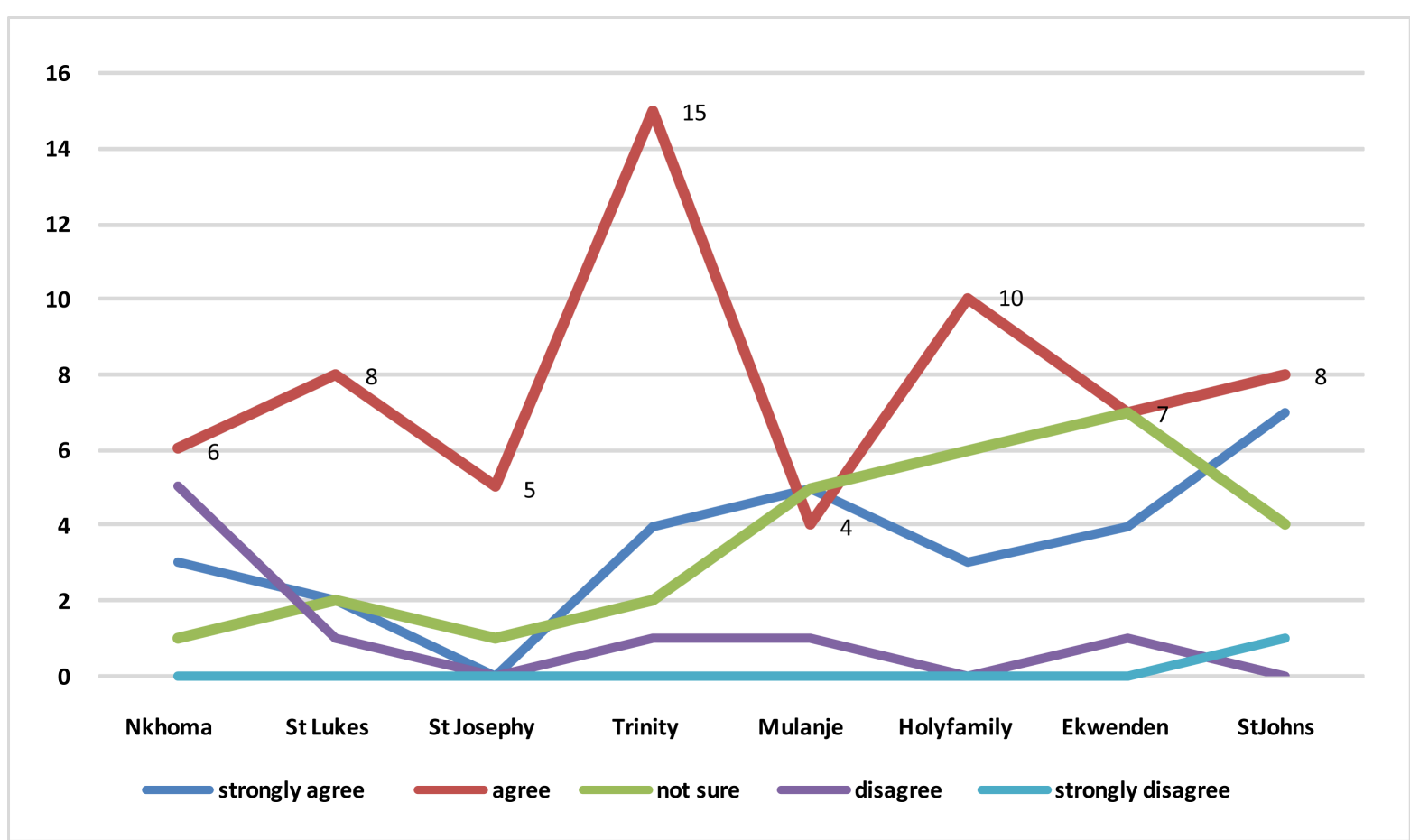

Figure 4. Distribution of students on how their nursing program is gender sensitive.

group in both the class and at the clinical area $=$. But in the same college $46.7 \%$ (7) $n=15$ of the students agreed that indeed the nurse tutors have the ability to act as a guide as opposed to dominating the group of the students. While $40 \%$ (6) $n=15$ of the nurse tutors in Ekwendeni nursing college agreed that they act as a guide to students rather than dominating in the group. But 42.1\% (8) $n=19$ of the students in Ekwendeni Nursing College agreed that nurse tutors act as guide rather than dominating the group. Generally 48.8\% (40) $n=82$ of the nurse tutors from different colleges agreed that they act as a guide to students rather than dominating the group. Moreover, $47.8 \%$ (61) $n=129$ of the students from different nursing colleges agreed that their nurse tutors act as a guide rather than dominating during teaching both in the class and at the clinical area. However, a lot of nurse tutors explained that the increased dominance during teaching comes in on topics that students have limited experience like anatomy and physiology. Student do not participate actively during teaching, thereby causing cognitive dominance of the nurse tutors during teaching.

The teaching psychomotor performance of nurse tutors on guiding clinical students on resource mobilisation was also looked into during analysis. 53.3\% of the nurse tutors in Ekwendeni Nursing College agreed that they guide nursing students on clinical resource mobilisation during teaching at the clinical area. Moreover, 63.1\% of the students from Ekwendeni Nursing College also agreed that the nurse tutors guide the students on clinical resource mobilisation. And there were $50 \%$ of the students from St. Joseph who agreed that the nurse tutors guide students on clinical resource mobilisation during teaching in the clinical area. However, $56 \%(46) n=82$ of the nurse tutors from all the nursing colleges in Malawi agreed that they guide the nursing students on resource mobilisation both in the classroom during procedure demonstration and at the clinical area. in addition $56.5 \%$ (73) $n=129$ of the students from different colleges of nursing agreed that nurse tutors guide nursing students on resource mobilisation during teaching particularly in the clinical area. This means that both students and nurse tutors are agreeing that the psychomotor performance of the nurse tutor on resource mobilisation is generally met during teaching both in class and at the clinical area. But a lot of nurse tutors pointed out that they struggle to mobilise resources due to limited funding. Many procedures are demonstrated to students under equipment improvisations (see Table 2).

Furthermore, in Table 1, the nurse tutors psychomotor performance of discharging skills in accordance to ward policy was also assessed. $43.8 \%$ of the nurse tutors in Nkhoma Nursing College agreed that they help the students to perform skills in accordance to ward policy during clinical teaching. But $73.3 \%$ of the students in the same Nkhoma nursing College agreed that nurse tutors in this college help them perform skills in accordance to 
Table 1. Distribution of the nurse tutors and students on tutor performance in different colleges.

\begin{tabular}{|c|c|c|c|c|c|c|c|c|c|c|c|c|c|c|c|c|c|c|c|}
\hline \multicolumn{2}{|l|}{ VARIABLE } & \multicolumn{18}{|c|}{ In which college do you teach or learn } \\
\hline \multirow{2}{*}{$\begin{array}{l}\text { Cognitive/affective/ } \\
\text { psychomotor }\end{array}$} & \multirow[t]{2}{*}{ Co-variates } & \multicolumn{2}{|c|}{ Nkhoma } & \multicolumn{2}{|c|}{ St. Lukes } & \multicolumn{2}{|c|}{ St Joseph } & \multicolumn{2}{|c|}{ Trinity } & \multicolumn{2}{|c|}{ Mulanje } & \multicolumn{2}{|c|}{ Holly family } & \multicolumn{2}{|c|}{ Ekwendeni } & \multicolumn{2}{|c|}{ St Johns } & \multicolumn{2}{|c|}{ TOTAL } \\
\hline & & tut & stud & tut & stud & tut & stud & tut & stud & tut & stud & tut & stud & tut & stud & tut & stude & tutor & stude \\
\hline \multirow{6}{*}{$\begin{array}{l}\text { Ability to act } \\
\text { as a guide as } \\
\text { opposed to } \\
\text { dominating } \\
\text { the group }\end{array}$} & Strongly agree & 7 & 3 & 2 & 2 & 0 & 1 & 2 & 5 & 4 & 5 & 8 & 2 & 1 & 2 & 2 & 4 & 26 & 24 \\
\hline & Agree & 7 & 7 & 3 & 6 & 3 & 2 & 2 & 10 & 4 & 4 & 5 & 13 & 6 & 8 & 10 & 11 & 40 & 61 \\
\hline & Not sure & 2 & 4 & 0 & 4 & 1 & 2 & 1 & 4 & 2 & 4 & 0 & 3 & 5 & 7 & 1 & 3 & 12 & 31 \\
\hline & Disagree & 0 & 1 & 0 & 0 & 0 & 1 & 0 & 3 & 0 & 2 & 1 & 1 & 2 & 2 & 0 & 1 & 3 & 11 \\
\hline & Strongly disagree & 0 & 0 & 0 & 1 & 0 & 0 & 0 & 0 & 0 & 0 & 0 & 0 & 1 & 0 & 0 & 1 & 1 & 2 \\
\hline & TOTAL & 16 & 15 & 5 & 13 & 4 & 6 & 5 & 22 & 10 & 15 & 14 & 19 & 15 & 19 & 13 & 20 & 82 & 129 \\
\hline \multirow{6}{*}{$\begin{array}{l}\text { Inadequate } \\
\text { attention to } \\
\text { related strategies } \\
\text { that maximise } \\
\text { success }\end{array}$} & Strongly agree & 6 & 2 & 1 & 1 & 0 & 1 & 3 & 0 & 3 & 4 & 3 & 3 & 5 & 3 & 4 & 4 & 27 & 18 \\
\hline & Agree & 2 & 3 & 3 & 4 & 0 & 2 & 0 & 4 & 3 & 5 & 6 & 8 & 4 & 2 & 6 & 5 & 24 & 33 \\
\hline & Not sure & 7 & 7 & 1 & 5 & 2 & 1 & 0 & 8 & 3 & 5 & 2 & 6 & 3 & 10 & 3 & 7 & 21 & 49 \\
\hline & Disagree & 1 & 3 & 0 & 2 & 0 & 2 & 1 & 8 & 1 & 1 & 3 & 2 & 3 & 4 & 0 & 3 & 9 & 25 \\
\hline & Strongly disagree & 0 & 0 & 0 & 1 & 0 & 0 & 1 & 2 & 0 & 0 & 0 & 0 & 0 & 0 & 0 & 1 & 1 & 4 \\
\hline & TOTAL & 16 & 15 & 5 & 13 & 4 & 6 & 5 & 22 & 10 & 15 & 14 & 19 & 15 & 19 & 13 & 20 & 82 & 129 \\
\hline \multirow{6}{*}{$\begin{array}{l}\text { Appropriate } \\
\text { personal and } \\
\text { professional } \\
\text { attitudes and } \\
\text { practices }\end{array}$} & Strongly agree & 5 & 2 & 2 & 1 & 2 & 1 & 1 & 4 & 3 & 3 & 5 & 4 & 4 & 3 & 4 & 4 & 26 & 22 \\
\hline & Agree & 8 & 10 & 3 & 8 & 2 & 3 & 2 & 13 & 5 & 8 & 8 & 13 & 8 & 8 & 8 & 10 & 44 & 73 \\
\hline & Not sure & 3 & 2 & 0 & 3 & 0 & 1 & 0 & 5 & 1 & 4 & 1 & 1 & 1 & 5 & 1 & 5 & 7 & 26 \\
\hline & Disagree & 0 & 0 & 0 & 0 & 0 & 1 & 2 & 0 & 1 & 0 & 0 & 1 & 2 & 3 & 0 & 0 & 5 & 5 \\
\hline & Strongly disagree & 0 & 1 & 0 & 1 & 0 & 0 & 0 & 0 & 0 & 0 & 0 & 0 & 0 & 0 & 0 & 1 & $\mathbf{0}$ & 3 \\
\hline & TOTAL & 16 & 15 & 5 & 13 & 4 & 6 & 5 & 22 & 10 & 15 & 14 & 19 & 15 & 19 & 13 & 20 & 82 & 129 \\
\hline \multirow{6}{*}{$\begin{array}{l}\text { Willingness } \\
\text { to take } \\
\text { responsibility } \\
\text { for their own } \\
\text { behaviour }\end{array}$} & Strongly agree & 3 & 2 & 0 & 3 & 0 & 1 & 2 & 3 & 3 & 4 & 4 & 3 & 5 & 4 & 2 & 6 & 19 & 26 \\
\hline & Agree & 10 & 4 & 4 & 3 & 3 & 3 & 3 & 13 & 5 & 5 & 9 & 13 & 3 & 11 & 8 & 9 & 45 & 61 \\
\hline & Not sure & 2 & 6 & 1 & 4 & 1 & 1 & 0 & 4 & 2 & 4 & 1 & 2 & 2 & 3 & 2 & 2 & 11 & 26 \\
\hline & Disagree & 1 & 2 & 0 & 2 & 0 & 1 & 0 & 2 & 0 & 2 & 0 & 1 & 4 & 1 & 1 & 0 & 6 & 11 \\
\hline & Strongly disagree & 0 & 1 & 0 & 1 & 0 & 0 & 0 & 0 & 0 & 0 & 0 & 0 & 1 & 0 & 0 & 3 & 1 & 5 \\
\hline & TOTAL & 16 & 15 & 5 & 13 & 4 & 6 & 5 & 22 & 10 & 15 & 14 & 19 & 15 & 19 & 13 & 20 & 82 & 129 \\
\hline
\end{tabular}

ward policy. At Holy Family Nursing College, 35.7\% of the nurse tutors agreed that they help students to perform in accordance to ward policy. However, $73.6 \%$ of the students agreed that their nurse tutors help them during teaching in the clinical area in accordance to the ward policy. Generally, $45.1 \%$ (37) $n=82$ of the nurse tutors from different nursing colleges in Malawi agreed that they help nursing students to perform at the clinical area in accordance to the ward nursing policy. It was very encouraging to note that $60.5 \%$ (78) $n=129$ of the nursing students agreed that the nurse tutors help the nurse students in different colleges to perform at the clinical area in accordance to the ward policy. Some nurse tutors pointed out that the critical challenge is limited availability and exposure to ward policies by the nurse tutors.

Provision of ongoing feedback to students for growth during teaching both in class and at the clinical area was also assessed as a psychomotor performance to nurse tutors (see Table 2). $80 \%$ of the nurse tutors in St. Lukes Nursing College agreed that they provide ongoing feedback to nursing students during teaching for growth both in class and at the clinical area. While only $38.5 \%$ of the nursing students from the same St. Lukes Nursing College agreed that their nurse tutors provide ongoing feedback to the students during teaching both in class and at the clinical area. Furthermore 50\% of the nurse tutors in Mulanje Nursing College agreed that they provide nursing students with ongoing feedback during teaching. But $53.3 \%$ of the nursing students agreed that their tutors provide ongoing feedback to students for growth during teaching both in class and at the clinical area. $46.3 \%$ (38) $n=82$ of the nurse tutors from different nursing colleges agreed that they provide ongoing feedback to nursing students during teaching both in class and at the clinical area. However, most nurse tutors noted that provision of feedback is mainly compromised when the nurse tutors have limited interaction with the students.

$60.5 \%$ (78) $n=129$ of the nursing students from different nursing colleges agreed that the nurse tutors provide ongoing feedback to nursing students during teaching both in class and at the clinical area. This entails that many nurse tutors disagree that they provide ongoing feedback to nursing students during teaching. Therefore, the psychomotor performance of nurse tutors on provision of ongoing feedback to students during teaching is very limited both in class and at the clinical area. 
Table 2. Distribution of the nurse tutors and students on performance in different nursing colleges.

\begin{tabular}{|c|c|c|c|c|c|c|c|c|c|c|c|c|c|c|c|c|c|c|c|}
\hline \multicolumn{2}{|l|}{ VARIABLE } & \multicolumn{18}{|c|}{ In which college do you teach or learn } \\
\hline \multirow{2}{*}{$\begin{array}{l}\text { Cognitive/affective/ } \\
\text { psychomotor }\end{array}$} & \multirow[t]{2}{*}{ Co-variates } & \multicolumn{2}{|c|}{ Nkhoma } & \multicolumn{2}{|c|}{ St. Lukes } & \multicolumn{2}{|c|}{ St Joseph } & \multicolumn{2}{|c|}{ Trinity } & \multicolumn{2}{|c|}{ Mulanje } & \multicolumn{2}{|c|}{ Holly family } & \multicolumn{2}{|c|}{ Ekwendeni } & \multicolumn{2}{|c|}{ St Johns } & \multicolumn{2}{|c|}{ TOTAL } \\
\hline & & tut & stud & tut & stud & tut & stud & tut & stud & tut & stud & tut & stud & tut & stud & tut & stude & tutor & stude \\
\hline & Strongly agree & 9 & 3 & 1 & 2 & 3 & 1 & 3 & 3 & 4 & 8 & 9 & 3 & 7 & 3 & 7 & 6 & 43 & 29 \\
\hline \multirow{3}{*}{$\begin{array}{l}\text { Help student } \\
\text { perform skills } \\
\text { in accordance } \\
\text { with ward policy }\end{array}$} & Agree & 7 & 11 & 4 & 8 & 1 & 3 & 2 & 16 & 5 & 5 & 5 & 14 & 7 & 10 & 6 & 11 & 37 & 78 \\
\hline & Not sure & 0 & 0 & 0 & 0 & 0 & 2 & 0 & 1 & 0 & 2 & 0 & 0 & 1 & 5 & 0 & 3 & 1 & 13 \\
\hline & Disagree & 0 & 1 & 0 & 0 & 0 & 0 & 0 & 2 & 1 & 0 & 0 & 0 & 0 & 1 & 0 & 0 & 1 & 4 \\
\hline \multirow[t]{3}{*}{$0.006 \mathrm{t} / 0.005 \mathrm{st}$} & Strongly disagree & 0 & 0 & 0 & 3 & 0 & 0 & 0 & 0 & 0 & 0 & 0 & 2 & 0 & 0 & 0 & 0 & 0 & 5 \\
\hline & TOTAL & 16 & 15 & 5 & 13 & 4 & 6 & 5 & 22 & 10 & 15 & 14 & 19 & 15 & 19 & 13 & 20 & 82 & 129 \\
\hline & Strongly agree & 6 & 3 & 1 & 2 & 1 & 1 & 2 & 3 & 4 & 4 & 6 & 3 & 6 & 2 & 7 & 4 & 7 & 22 \\
\hline \multirow{3}{*}{$\begin{array}{l}\text { Provide ongoing } \\
\text { feedback to } \\
\text { the student } \\
\text { for growth }\end{array}$} & Agree & 7 & 8 & 4 & 5 & 3 & 3 & 3 & 18 & 5 & 8 & 7 & 11 & 5 & 12 & 4 & 13 & 4 & 78 \\
\hline & Not sure & 2 & 1 & 0 & 1 & 0 & 2 & 0 & 0 & 0 & 3 & 0 & 2 & 4 & 4 & 2 & 2 & 2 & 15 \\
\hline & Disagree & 1 & 2 & 0 & 3 & 0 & 0 & 0 & 1 & 0 & 0 & 1 & 2 & 0 & 1 & 0 & 1 & 0 & 10 \\
\hline \multirow[t]{3}{*}{$0.07 t / 0.069 s t$} & Strongly disagree & 0 & 1 & 0 & 2 & 0 & 0 & 0 & 0 & 1 & 0 & 0 & 1 & 0 & 0 & 0 & 0 & 0 & 4 \\
\hline & TOTAL & 16 & 15 & 5 & 13 & 4 & 6 & 5 & 22 & 10 & 15 & 14 & 19 & 15 & 19 & 13 & 20 & 13 & 129 \\
\hline & Strongly agree & 7 & 2 & 0 & 1 & 1 & 1 & 2 & 3 & 5 & 4 & 7 & 2 & 3 & 2 & 3 & 3 & 28 & 18 \\
\hline \multirow{3}{*}{$\begin{array}{l}\text { Moved group } \\
\text { actively in } \\
\text { positive direction }\end{array}$} & Agree & 5 & 9 & 5 & 6 & 2 & 2 & 3 & 15 & 3 & 9 & 7 & 14 & 9 & 11 & 6 & 16 & 40 & 82 \\
\hline & Not sure & 4 & 2 & 0 & 4 & 1 & 1 & 0 & 2 & 1 & 2 & 0 & 1 & 3 & 3 & 3 & 1 & 12 & 16 \\
\hline & Disagree & 0 & 2 & 0 & 2 & 0 & 2 & 0 & 2 & 1 & 0 & 0 & 1 & 0 & 3 & 1 & 0 & 2 & 12 \\
\hline \multirow[t]{3}{*}{$0.1 \mathrm{t} / 0.085 s t$} & Strongly disagree & 0 & 0 & 0 & 0 & 0 & 0 & 0 & 0 & 0 & 0 & 0 & 1 & 0 & 0 & 0 & 0 & 0 & 1 \\
\hline & TOTAL & 16 & 15 & 5 & 13 & 4 & 6 & 5 & 22 & 10 & 15 & 14 & 19 & 15 & 19 & 13 & 20 & 82 & 129 \\
\hline & Strongly agree & 6 & 3 & 2 & 3 & 0 & 0 & 2 & 6 & 4 & 6 & 7 & 3 & 4 & 0 & 3 & 5 & 28 & 26 \\
\hline \multirow{3}{*}{$\begin{array}{l}\text { Formulated } \\
\text { questions to } \\
\text { stimulate } \\
\text { further inquiry }\end{array}$} & Agree & 7 & 6 & 3 & 6 & 3 & 2 & 3 & 12 & 5 & 5 & 6 & 14 & 6 & 14 & 10 & 12 & 43 & 71 \\
\hline & Not sure & 3 & 5 & 0 & 3 & 1 & 3 & 0 & 0 & 0 & 3 & 1 & 1 & 4 & 5 & 0 & 2 & 9 & 22 \\
\hline & Disagree & 0 & 1 & 0 & 0 & 0 & 0 & 0 & 4 & 1 & 1 & 0 & 1 & 1 & 0 & 0 & 1 & 2 & 8 \\
\hline \multirow[t]{2}{*}{0.05 st } & Strongly disagree & 0 & 0 & 0 & 1 & 0 & 1 & 0 & 0 & 0 & 0 & 0 & 0 & 0 & 0 & 0 & 0 & 0 & 2 \\
\hline & TOTAL & 16 & 15 & 5 & 13 & 4 & 6 & 5 & 22 & 10 & 15 & 14 & 19 & 15 & 19 & 13 & 20 & 82 & 129 \\
\hline
\end{tabular}

When the nurse tutors were asked on how they improve their teaching psychomotor performance, a nurse tutor from Nkhoma Nursing College added that:

I make sure that I don't miss my classes, and I make sure that I follow the curriculum when am preparing my notes so that I don't go overboard, and I make sure that I take maybe content that is too little and then I consult other people, when there is need to, other tutors who have been in the profession longer than myself when I see that am not conversant with other things. And then I also continuously practice in the skills lab on my own just to remind myself or to keep up to date my skills on performing different sets of skill that I need.

Therefore, punctuality, curriculum abidance and consultations improve the nurse tutor teaching cognitive, affective and psychomotor performance in Malawi nursing colleges.

The concept of formulating questions to stimulate students' further inquiry during clinical teaching by nurse tutors was also analysed as a cognitive performance (see Table 2). 43.7\% of the nurse tutors from Nkhoma Nursing College agreed that they formulate questions to stimulate further inquiry to students during teaching. While $40 \%$ of the students from Nkhoma Nursing College agreed that nurse tutors in their college formulate questions to stimulate further inquiry during teaching both in class and at the clinical area. $75 \%$ of nurse tutors in St. Joseph Nursing College agreed that they formulate questions to stimulate further inquiry to students during teaching. But only 33.3\% of the students from St. Joseph Nursing College agreed that their nurse tutors formulate questions that stimulate students' further inquiry. The main challenge is that most nurse tutors 
are not having high qualification like master's degree that help them to articulate properly during teaching. However, 52.4 (43) $n=82$ of the nurse tutors from different nursing colleges agreed that they formulate questions that stimulate further inquiry during teaching the nursing students in class and at the clinical area. 55\% (71) $n=129$ of the students from different nursing colleges agreed that their nurse tutors formulate questions that stimulate them for further inquiry. Therefore, it entails that the cognitive performance of nurse tutors on formulating questions is above average in all nursing colleges.

$50 \%$ of the nurse tutors from Nkhoma Nursing College agreed that they alleviate students stress in the clinical area during teaching as an affective performance. But only $25 \%$ of the students from Nkhoma Nursing College agreed that their nurse tutors alleviate students stress in the clinical area during teaching. Moreover, $64.2 \%$ of the nurse tutors from Holy Family Nursing College agreed that they alleviate students stress in the clinical area during teaching. But, only $26.3 \%$ of the students from Holy Family Nursing College agreed that they alleviate students stress during teaching. Generally from different nursing colleges 48.8\% (40) $n=82$ of the nurse tutors agreed that they alleviate the students stress in the clinical area during teaching. However, only $45.7 \%$ (59) $n=129$ of the nursing students from different nursing colleges in Malawi agreed that their nurse tutors alleviate students stress during teaching both in class and at the clinical area. This therefore, this study suggests that nurse tutors affective and psychomotor performance on student stress management during teaching in class and at the clinical area is very low. The main challenge, still focus on the availability of the nurse tutors, in the clinical area. Students are sent to different hospital for clinical practice, but follow up of the students to these hospital depend on funding from the college administration. Most nurse tutors pointed out that in a six weeks allocation students may be followed only three to five days by their clinical instructors.

Another important area where teaching psychomotor performance of the nurse tutors was checked is on provision of student opportunities for personal practice at the clinical area. $40 \%$ of the nurse tutors from St Luke Nursing College agreed that they provide students with opportunities for personal practice in the clinical area during teaching. $46.2 \%$ of the students from the same St. Luke Nursing College agreed that their nurse tutors provide them with opportunities for personal practice during teaching at the clinical area.

At St. Joseph $80 \%$ of the students disagreed that their nurse tutors provide them with an opportunities to practice in the clinical area during teaching. But $50 \%$ of the nurse tutors in the same St. Joseph Nursing College agreed that they provide their students with the opportunities to practice in the clinical area. However, in general, $47.5 \%$ (39) $n=82$ of the nurse tutors from different nursing colleges strongly agreed that they provide the nursing students with opportunities to practice in the clinical area during teaching. 26.4\% (34) $n=129$ of the students from different nursing colleges strongly agreed that their nurse tutors provide them with opportunities to practice in the clinical area during teaching. Therefore, it is clearly that nurse tutors psychomotor performance on the provision of students an opportunity to practice in the clinical area is very low in Malawi nursing colleges. The major challenge on commonly on the number of hours that the students are exposed to their clinical instructors thus nurse tutors. Students are mostly found with the ward nurses who have limited skills on clinical instructions.

The fitting of the training to the skills level of the students was another teaching psychomotor performance that was assessed in the nurse tutors. 56.2\% of the nurse tutors in Nkhoma Nursing College agreed that they fit the training material to the skills level of the students. But only $46.6 \%$ of the students from the same Nkhoma Nursing College agreed that their nurse tutors fit the training material to the skills level of the students during teaching both in class and at the clinical area. However, $40 \%$ of the students from Nkhoma Nursing College disagreed that nurse tutors fit their training material to the skills level of the students during teaching. At St. Johns Nursing College, $46.1 \%$ of the nurse tutors agree that they fit the training material to the skills level of the students during teaching. But $70 \%$ of the students agreed that their nurse tutors fit the training material to the skills level of the students during teaching. Generally after asking the question to all eight nursing colleges, 53.7\% (44) $n=82$ of the nurse tutors from all the colleges agreed that they always fit the training material to the skills level of the students during teaching both in class and at the clinical area. But 55\% (71) $n=129$ of the nursing students from all the nursing colleges in Malawi agreed that their nurse tutors fit the training material to the skills level of the students during teaching. Therefore, the cognitive and psychomotor performance of the nurse tutors in Malawi on fitting the training material to the skills level of the students during teaching has been very high as both the students and the nurse tutors agree that they do fit the training. However, nurse tutors complained that due to shortage of nursing staff in the hospital, first year students are seen performing procedures that they have not yet learnt in class. 
But apart from fitting the training, some nurse tutors pointed out that they must also be goal oriented when teaching, for example a nurse tutor from St. Joseph Nursing College noted that:

Maybe I would say people say I am goal oriented and since I am goal oriented I don't allow people to do other things apart from the things I want them to do; if I am goal oriented then it means we have to meet the objectives you have set. And I make sure that students work in the limit to achieve those objectives; let's say maybe you have been assigned to do certain amount of work and you set limits. By such...such time I want this one to be complete and you have to make sure that at such time that job or that work is completed by students and me. And if students are not working accordingly then you have to make a proper follow up and make sure that you facilitate that process. When am talking to the student am audible enough the student are able to get what am saying!

So, if nurse tutors are goal oriented they can provide quality services to the student thereby promoting health in the clinical area.

25\% of the nurse tutors in Trinity Nursing College agreed that they pair the experienced skills based health education providers with the new students at the clinical area.

But $54.5 \%$ of the nursing students agreed that their nurse tutors pair them with the experienced skill based health education providers. But 50\% of the nurse tutors from St. Johns Nursing College disagreed that they pair the experienced skill based health education providers with their new students in the clinical area. While only 20\% of the students from St. Johns Nursing College disagreed that their nurse tutors pair them to the experienced skill based health education providers in the clinical area. However, $46.3 \%$ (38) $n=82$ of the nurse tutors from all the eight nursing colleges agreed that they pair the nursing students to the experienced skill based health education providers in the in clinical area. And 48\% (62) $n=129$ of the students from all the eight nursing colleges in Malawi agreed that their nurse tutors pair them to the experienced skill based health education providers during teaching in the clinical area. In this psychomotor performance item, it is clear that nurse tutors do pair nursing students to the qualified health education providers who would help in the clinical training for quality care and development of the students on clinical skills. However, pairing of student from different level of training is difficult due to different clinical student allocation. It might happen that first year students who are doing clinical fundamental nursing are paired with third year students who are doing maternal nursing. In such conditions the type of the wards might be different thereby denying the chance of pairing for mentoring.

The nurse tutor affective performance on the students' encouragement on team work was also assessed. 64.2\% of the nurse tutors from Holy Family Nursing Colleges agreed that they encourage students on team work during teaching both in class and at the clinical area. And 63.2\% of students from Holy Family Nursing College agreed that their nurse tutors encourage the students on team work during teaching both in class and at the clinical area. $75 \%$ of the nurse tutors from St. Joseph agreed that they encourage team work among students during teaching. Moreover, 66.6\% of the nursing students from the same St. Joseph Nursing College agreed that their nurse tutors encourage them on team work during teaching both in class and at the clinical area. In addition, at St. Johns Nursing College 53.8\% of the nurse tutors agreed that they encourage nursing students to team work during teaching. $50 \%$ of the nursing students from St. Johns Nursing College also agreed that their nurse tutors encourage them to team work during teaching both in class and at the clinical area. But generally after assessing in all the eight nursing colleges $52.4 \%$ (43) $n=82$ of the nurse tutors agreed that they encourage nursing students in their respective colleges to team work during teaching. 51.9\% (67) $n=129$ of the students from all the eight nursing colleges agreed that their nurse tutors encourage them to team work during teaching both in class and at the clinical area. Therefore, nurse tutor teaching affective performance level on encouraging of the students to team work during teaching is very high in Malawi nursing colleges. However, when bivariate analysis was used to compare the independent variable type of the college where the nurse tutor is teaching and the dependent variable, nurse tutors encouragement of the team work. The null hypothesis that type of the nursing college is not correlated to nurse tutors encouragement to team work was rejected. This is because the p-value was $0.033<\mathrm{p}=0.05$. This suggests that type of the college was highly correlated to nurse tutors encouragement of the students to team work during teaching. The result indicates that nurse tutors encouragement to team work of the students depends on the type of the college where the nurse tutor is working. Although some students said that the big challenge of team work is laziness of some students who do not participate fully in group discussions.

Another nurse tutor from Nkhoma Nursing College during in-depth interview also pointed out that they must be humble when approached by students: 
My presentation I don't go there proposing like am too senior to the students. I really make sure that I humble myself before my students so that I am closer to their level, so that they understand what I am telling them because many students we teach they have a degree of low self-esteem. We are teaching nurse NMTs; nurse mid-wife technician, so you look at somebody and with a degree or masters and in my case to them they only look at your masters degree not what you are teaching so if you are not careful you don't deliver anything they just look at you as somebody with a lot of pride so by the end of the day they will only pick any comment you say they will rate, because she is much educated this is why she is saying so; they will rate you with academic status or your financial status if they know you. So, I really make sure that I just deliver the content without offending my students and if I happened that I offended them I say sorry so that by the end of the day they don't grasp that negative comment but they keep the main message.

Therefore, being humble to students during teaching, although you have high qualification, promotes team work thereby increasing the interest and performance of the nurse tutor.

The nurse tutors were also asked on how they generally perform with the students in the clinical area, particularly on the facilitation of the team work. And one of the nurse tutors from Ekwendeni Nursing College said:

Students usually have a duty roster and you have to make sure that everybody is following the duty allocation. Secondly these students are supposed to have objectives for the day so you make sure that you check whatever the student has planned to do from their objectives. And from your own plans, you also identify tasks that have to be done together with the students depending also on the ward that you are working. So you still have to work hand in hand to identify appropriate clients and patients with the students because sometimes they may not know clients or patients to choose. So, you have to facilitate that learning process by choosing the system to choose appropriately or with the actual teaching usually when I need to teach them according to the deadlines that they have. and also mainly when you have arrive in the ward, first of all you meet the students you have to discover before you start, if everybody and everything is ok then after you have gone through objectives then you also select some procedures that you want to do. Then after you have achieved whatever you had planned for the day before you close you also meet the group and discuss what they have learnt that day how best they could do those things and how they plan to improve so you work with them and give them the necessary feedback.

Therefore, facilitation of clinical student objectives and selection of appropriate clients for student learning enhance the teaching psychomotor performance of the nurse tutors in the clinical area.

The psychomotor performance of the nurse tutors working with students in the laboratory was also measured. 87.5\% of the nurse tutors from Nkhoma Nursing College agreed that they work effectively in the laboratory with students to improve their skills. While $60 \%$ of the students from Nkhoma Nursing College agreed that their nurse tutors work effectively in the laboratory with students to improve their skills. $60 \%$ of the nurse tutors from Mulanje Nursing College also strongly agreed that they work effectively with their students in the laboratory to improve their nursing skills. But 33.3\% of the students from Mulanje Nursing College agreed that their nurse tutors work effectively with them in the laboratory to improve their skills. $73.3 \%$ of the nurse tutors in Ekwendeni Nursing College agreed that they work effectively with the nursing students in the laboratory to improve their nursing skills. However, generally $52.4 \%$ (43) $n=82$ of the nurse tutors from all the eight nursing colleges agreed that they work effectively with the students in the laboratory to improve their skills. But $55 \%$ (71) $n=129$ of the nursing students from different nursing colleges in the country agreed that their nurse tutors work effectively with them in the laboratory to improve their skills. This suggests that nurse tutors psychomotor performance of working effectively with students in the laboratory is above average and it helps to improve the students' clinical skills. But when Spearman Correlation Coefficient was used to compare the type of the nursing college and the effective working with students in the laboratory by nurse tutors, the outcome of the p-value was $0.054 \leq \mathrm{p}=0.05$. This suggests that there is a board-line correlation between the type of the nursing college and the nurse tutors effectively working with students in the laboratory. This indicates that effective working of the nurse tutors in the laboratory with students is influenced by the type of the nursing college where the nurse tutor is working. But some lecturers pointed out that teaching students in the laboratory becomes a challenges due to large numbers and limited equipment.

\section{Association of Nurse Tutor Work Experience and Student Study Experience on Tutors Performance}

The variable of inadequate clinical orientation to students was measured as a nurse tutor psychomotor performance to see the statistical association using logistic regression in Table 3. The logistic model opted the 
Table 3. Association of tutors work experience, students study experience and tutor clinical performance.

\begin{tabular}{|c|c|c|c|c|c|c|c|c|c|c|c|c|}
\hline \multirow{3}{*}{$\begin{array}{c}\text { Tutor who AGREE } \\
\text { on PERFORMANCE } \\
\text { variables }\end{array}$} & \multicolumn{6}{|c|}{ Tutors work experience } & \multicolumn{6}{|c|}{ Students study experience } \\
\hline & \multirow[t]{2}{*}{ B } & \multirow[t]{2}{*}{ WARD } & \multirow[t]{2}{*}{ sig } & \multirow[t]{2}{*}{ ODD } & \multicolumn{2}{|c|}{$\begin{array}{c}\text { Confidenc } \\
\text { interval }\end{array}$} & \multirow[t]{2}{*}{ B } & \multirow[t]{2}{*}{ WARD } & \multirow[t]{2}{*}{ sig } & \multirow[t]{2}{*}{ ODD } & \multicolumn{2}{|c|}{$\begin{array}{c}\text { Confidenc } \\
\text { interval }\end{array}$} \\
\hline & & & & & Lower & Upper & & & & & Lower & Upper \\
\hline Inadequate clinica orientation & -1.196 & 4.152 & 0.042 & 0.302 & 0.096 & 0.955 & 0.031 & 0.005 & 0.944 & 1.032 & 0.430 & 2.474 \\
\hline Too little-time to clinical practice & 0.514 & 0.572 & 0.450 & 1.672 & 0.441 & 6.344 & 1.844 & 5.165 & 0.023 & 6.324 & 1.289 & 31.030 \\
\hline Infusion health without foundation & 0.360 & 0.227 & 0.634 & 1.433 & 0.326 & 6.295 & -1.731 & 4.370 & 0.037 & 0.177 & 0.035 & 0.898 \\
\hline Weak leadership & -0.239 & 0.121 & 0.728 & 0.787 & 0.204 & 3.039 & -1.080 & 4.735 & 0.030 & 0.340 & 0.128 & 0.898 \\
\hline Lack of teaching material & -0.024 & 0.002 & 0.967 & 0.976 & 0.312 & 3.054 & -0.063 & 0.022 & 0.882 & 0.939 & 0.407 & 2.163 \\
\hline Inadequate funding & 0.013 & 0.000 & 0.985 & 1.013 & 0.271 & 3.793 & -0.989 & 6.688 & 0.010 & 0.372 & 0.176 & 0.787 \\
\hline Recognition behaviour & 0.523 & 0.450 & 0.502 & 1.687 & 0.366 & 7.771 & 0.612 & 1.855 & 0.173 & 1.845 & 0.764 & 4.452 \\
\hline Willingness to take responsibility & -0.762 & 0.732 & 0.392 & 0.467 & 0.081 & 2.675 & -0.161 & 0.097 & 0.756 & 0.851 & 0.308 & 2.351 \\
\hline Concerned with Social student issues & 0.447 & 0.270 & 0.603 & 1.564 & 0.290 & 8.449 & 0.105 & 0.033 & 0.856 & 1.110 & 0.358 & 3.446 \\
\hline Sense of student care & 0.341 & 0.158 & 0.691 & 1.406 & 0.262 & 7.550 & -0.462 & 0.679 & 0.410 & 0.630 & 0.210 & 1.889 \\
\hline Accurate teaching knowledge & -1.119 & 2.513 & 0.113 & 0.327 & 0.082 & 1.303 & 0.091 & 0.036 & 0.850 & 1.095 & 0.427 & 2.807 \\
\hline
\end{tabular}

This is a logistic regression models with probability classification cut-off of 0.5 and the entry point of p-value of 0.05 in statistics of Hosmer-Leme show goodness of-fit. Basing on method of ENTER, the maximum iteration of more than 20 items were entered. Only those that show statistical significance were tabulated. The equation had a probability of $95 \%$ confidence interval. The OR interpretation of above 1 was adopted for the predictor variables of nurse tutor experience and student study experience separately. All the categorical or dependent variables and the predictor/independent variables were first tested in the bivariate analysis at p-value of 0.05 . All constant values were not tabulated although the models produced due to table spacing. The degree of freedom was set at 1 . All nurse tutor performance variables were regarded as dependent variables and nurse tutor work experience and student study experience which are independent or predicator variables. All categorical variables were dichotomizedly coded correctly (with $0=$ disagree or lack of the characteristic (); 1 = agree, or the presence of the characteristics. The disagree was treated as a constant value.

probability for stepwise of the entry level of 0.05 and the removal level of 0.10 . In this the model, which was omnibus test model of coefficient the outcome of the odds ratio was OR $\leq 0.302$; $95 \%$ CI $(0.096 \pm 2.955)$; p $\geq$ 0.042. This was after predictor variable nurse tutor work experience was compared to dependent variable inadequate clinical orientation to students. In this outcome where the logistic method was ENTER, it clearly entails that the more years the nurse tutors have both in class and at the clinical area, the less likely that nurse tutors would have adequate clinical orientation to students during teaching in the clinical area. Even the Beta value of the analysis was showing a negative direction of relationship between the predictor variable and the dependent variable as it was $B=-1.196$. This means that for every increase in year of work for nurse tutors both in class and at the clinical area, there will be a decrease for the clinical orientation to students. Therefore, having more years of nurse tutor work experience in Malawi nursing colleges leads to nurse tutor limited or poor clinical orientation of students. Furthermore, this was the same in the students' perceptions as the omnibus test model of coefficient outcome of the odds ratio, Beta value, the Ward, correlations and the confidence interval were adopted. The results illustrated that $\mathrm{OR} \leq 1.032 ; 95 \% \mathrm{CI}(0.430 \pm 2.474) ; \mathrm{p} \geq 0.944$. In this outcome the probability was the main predictive values with standardisation as the specific residuals. This means that there was strong association between the predictor variable of student study experience and the dependent variable of inadequate clinical orientation to students by nurse tutors. Therefore, for every one year addition in the student study experience in all nursing colleges in Malawi, there would be 1.032 times of nurse tutors inadequate clinical orientation to students during teaching both in class and at the clinical area. Furthermore, students pointed out that the challenge of clinical orientation is the availability of the nurse tutors.

The psychomotor performance of the nurse tutors on little concentrated time on the learning tasks with student to clinical practice was also entered into the logistic model. This was done where the dependent variable was compared to the nurse tutor work experience as the predictor variable. This was done after dichotomising the predictor and dependent variables. In this logistic regression model the option of omnibus test of coefficient was used with probability for stepwise criteria of 0.05 in entry and 0.5 as the classification cut-off. Using the ENTER method the outcome of the odds ratio, Beta value, the Ward, correlations and the confidence interval were adopted. So, the results showed that $\mathrm{OR} \leq 1.672 ; 95 \% \mathrm{CI}(0.441 \pm 6.344) ; \mathrm{p} \geq 0.450$. This indicates that 
there is strong association between the predictor variable nurse tutor work experience and the dependent variable nurse tutors too little time to clinical practice during teaching. For every one year increase on the nurse tutor work experience there would be 1.672 times more likely that the nurse tutors have too little concentrated time on the student learning tasks to the clinical practice. Therefore, clearly entails that in Malawi nursing colleges, having more experience for nurse tutors would be resulting to poor nurse tutors performance on too little concentrated time with the students learning tasks in the clinical area for teaching.

Even the Beta Coefficient value of the Binary Logistic Regression equation showed a positive direction of relationship although in a decimal figure of $\mathrm{B}=0.514$. This illustrates that any increase in the nurse tutor work experience would result to slight increase of the performance of nurse tutor on concentrated time to students clinical practice for learning. Moreover, in another related omnibus test of coefficient model, it focused on the student study experience as the predictor variable in comparison with dependent variable of too little concentrated time with student clinical learning. The results of the model after using the ENTER method and probability for stepwise criteria of 0.05 in entry and 0.5 as the classification cut-off was OR $\leq 6.324 ; 95 \%$ CI (1.289 \pm 31.030); $\mathrm{p} \geq 0.023$. This also means that there is a strong association between student study experience and nurse tutors' concentrated time on student learning tasks at the clinical area. For every one year extra in the student study experience there would be a likelihood of 6.324 times more for nurse tutors to have little concentrated time to clinical practice on student learning tasks.

Even the Beta Coefficient value of the results was $B=1.844$. This showed that there is a positive direction of the relationship between student study experience and the nurse tutors little concentrates time with students learning tasks in the clinical area. For any increase in the student study experience in Malawi nursing colleges, there would be a likely increase of the nurse tutors to have too little concentrated time on student learning tasks in the clinical area.

Lack of teaching material is very devastating challenge among nurse tutors in Malawi and the variable was evaluated using the logistic regression analysis. In the omnibus test model coefficient, the probability for stepwise criteria was 0.05 at entry and 0.5 as the classification cut-off. This was done to compare the predictor variable nurse tutor work experience and the dependent variable nurse tutors lack of teaching material in the colleges and at the clinical area. The outcome of the model was an odds ratio of OR $\leq 0.976$; $95 \%$ CI $(0.312 \pm$ 3.054); $\mathrm{p} \geq 0.967$ (see Table 3). This indicates that there is no association between the nurse tutor work experience and the nurse tutors lack of teaching material both in class and at the clinical area. For every one year increase in nurse tutor work experience there would be a probability likelihood of 0.976 times for the nurse tutors to lack teaching materials. Therefore, the nurse tutor work experience does not associate with lacking of teaching materials in Malawi nursing colleges. Even the Beta Coefficient value showed $(B=-0.239)$ a negative direction of the relationship between the nurse tutors work experience and the nurse tutors lacking of teaching materials both in class and at the clinical area. This suggests that for any increase in nurse tutor work experience there would be a decrease in the nurse tutor lacking the teaching material in the nursing colleges during teaching both in class and at the clinical area. Moreover, in the student data when student study experience as a predictor variable was compared to the lack of teaching materials, there was no statistical association. This was done after omnibus test of model coefficient where the probability for stepwise criteria included 0.5 as the classification cut-off. The results of the equation revealed the odds ratio of OR $\leq 0.939 ; 95 \%$ CI $(0.407 \pm 2.163) ; p \geq 0.882$. This suggests that for every one year addition to the student study experience in all nursing colleges in Malawi there would be a probability likelihood of 0.939 times for nurse tutors to have lack of teaching materials. So, student study experience has very limited or no association with the lacking of materials for teaching in nursing colleges. For the Beta Coefficient value of the results (see Table 3), it clearly showed that $(B=-0.063)$ there is a negative direction of the relationship between student study experience and the lacking of teaching materials in nursing colleges. For any increase in years for the student study experience there would a decrease in the nurse tutors lacking of teaching materials both in class and at the clinical area. Therefore, lacking of teaching material is not associated with student study experience.

It has to be mentioned again that inadequate funding by nursing administration for teaching is also a major challenge as it was found to be associated with nurse tutor experience. This was done after using the binary logistic regression with omnibus test of model coefficient. In the model the predictive value of probability stepwise criteria of 0.05 at entry and 0.1 at removal and 0.5 as the classification cut-off. The results of the equation clearly showed the odds ratio of $\mathrm{OR} \leq 1.013$; $95 \% \mathrm{CI}(0.271 \pm 3.793)$; $\mathrm{p} \geq 0.985$. The model indicates that there is a strong association between predictor variable nurse tutor work experience and the dependent variable in- 
adequate nursing administrative funding for nurse tutor teaching in all the nursing colleges in the country. For every additional year of the nurse tutor work experience there would be a probability likelihood chance of 1.013 times more on the inadequate nursing administrative funding in the nursing colleges in Malawi. Therefore, more nurse tutor work experience has a probability likelihood chance of inadequate nursing administration funding in nursing colleges. Although the Beta Coefficient value was in a decimal point $(B=0.013)$ but it also illustrated the positive direction of the relationship between the nurse tutor work experience and the nursing administrations' inadequate funding to the teaching programs.

But the students had different perception towards the funding issue of their nursing colleges. Using the same logistic regression model, with omnibus test model of coefficient, the results of the odds ratio revealed OR $\leq$ $0.372 ; 95 \%$ CI $(0.176 \pm 0.787) ; \mathrm{p} \geq 0.010$. This means that there was no association between the student study experience and inadequate nursing administrative funding. For any one year addition to the student study experience there would be a probability likelihood chance of 0.372 times of nursing administration having inadequate funding. This means that nursing administration do not have a big problem with funding the nurse tutors during teaching. Moreover, the Beta Coefficient value from the binary logistic regression equation showed B = -0.989 . This is an illustration of negative direction of the relationship between the student study experience and the administrative inadequacy of funding the nurse tutors during teaching. So any increase in years to the student study experience would result to the decrease of the inadequacy of administrative funding in the nursing colleges. This entails that in nursing colleges the students feel that any increase in their study experience would not affect the funding structure of the nursing college.

The cognitive performance of the nurse tutors on accurate teaching knowledge and adequate personal comfort with teaching was also analysed using the logistic regression model. In the model the probability stepwise criteria of 0.05 was selected for entry level and 0.5 was also adopted as the classification cut-off point in the equation. This was done as predictor variable was compared with dependent variable accurate teaching knowledge and adequate personal comfort with teaching. The result of the equation included the odds ratio of $\mathrm{OR} \leq 0.327 ; 95 \% \mathrm{CI}(0.082 \pm 1.303) ; \mathrm{p} \geq 0.113$. This illustrate that there is no association between the predictor variable nurse tutor work experience and the accurate knowledge of teaching and adequate personal comfort with teaching. for every one year extra in the nurse tutor work experience there would be a likelihood chance of 0.327 times for the nurse tutors accurate teaching knowledge and adequate personal comfort with teaching students both in class and at the clinical area. Even in the Beta Coefficient results it clearly showed that $(\mathrm{B}=$ -1.119) there is a negative direction of the relationship between the predictor variable nurse tutor work experience and the dependent variable accurate teaching knowledge and the adequate personal comfort with teaching. If there is an increase in the student study experience in years there would also be a likely increase of the nurse tutors accuracy in teaching knowledge and adequacy in personal comfort with teaching. However, there were different perceptions from the students. Using the same logistic regression model where a probability stepwise criterion of 0.05 for entry was selected and the 0.5 as a classification cut-off point was also adopted. This was done to compare the student study experience as the predictor variable and the nurse tutors accurate knowledge in teaching and adequate personal comfort with teaching. The outcome which also included the odds ratio was $\mathrm{OR} \leq 1.095$; CI $(0.427 \pm 2.807) ; \mathrm{p} \geq 0.850$. This clarifies that there is strong association between student study experience and the nurse tutors accurate teaching knowledge and adequate personal comfort with teaching. The results from the regression analysis shows that if one year is added to the student study experience there would be a likelihood of 1.095 times more for the nurse tutors to have accurate teaching knowledge and adequate personal comfort with teaching. Even the Beta Coefficient value from the results showed that $(B=0.091)$ there is a positive direction of relationship between the predictor variable student study experience and the dependent variable nurse tutor accuracy in teaching knowledge and adequacy in personal comfort with teaching. This implies that in Malawi if there is any increase in years of student study experience there would also be an increase in the nurse tutor accuracy in teaching knowledge and adequacy of personal comfort with teaching both in class and at the clinical area.

\section{Discussion}

Generally, in this study it has been found that both nurse tutors and students are not impressed with nurse tutors cognitive, affective and psychomotor performance during teaching. This is also the same to students who clearly indicated dissatisfaction with the nurse tutors' cognitive, affective and psychomotor performance both in class 
and at the clinical area. It has been noticed that different nursing colleges in Malawi have different sense of support to students in the clinical area.

The concept of nurse tutor psychomotor performance on lecturing during the entire class period has a big problem to students' process of learning. In this study students have clearly described nurse tutors to be teaching the entire class period despite level of experience. Student cannot cope up with pressure of such learning. When the students are tired there is always need to let them relax and get extra energy through fresh air, nutrition and reduced thinking capacity. But when the students are continuously learning without resting, the concentration span of their brain is severely reduced, that cause poor contribution and participation. Attention and concentration are the most powerful assets of human beings, and if correctly used, they can have numerous benefits in education [19]. At the same time it is very difficult to master content if the concentration span is reduced. A descriptive survey was conducted to assess the impact of teaching time that is classes for two hour, on attention and concentration of student nurses. The finding showed that $44 \%$ students had good attention and concentration in the first two hours of learning, $46 \%$ students had an average attention and concentration and $10 \%$ of students had poor attention and concentration score during the teaching and learning activities. It is clear that teaching beyond 2hours continuously reduces concentration span of the nursing students. Another author [20] did a study to assess the ability of the students to recall content taught during a lecture. Results show that most of the students were able to recall the initial content of the lecture soon after the class which indicates that they were more attentive during the beginning of class and gradually they become less attentive. This study reveals that to achieve full attention and concentration of the students, lengthy classes should have breaks or some learning activities, to make the class enjoyable. It is important for the students to pay attention and concentrate because it enhances their competency and skills to memorize the content for a longer period of time. There are many factors which can affect attention and concentration of nursing students in the classroom, such as duration and method of teaching, novelty and repetition of topic, surrounding environment, interest and including health and emotional status. If nursing students do not pay attention during teaching learning activities, they will be involved in other activities such as private conversations, dropping pen or pencils, excessive movement of body parts, passing notes to others. The environment of a professional college is very challenging. When an individual enters in a professional college as a student she/he has to prepare himself for higher education which demands attention and concentration during classes for future growth. Therefore, it is a big challenge for nursing students to learn during the entire class period.

The psychomotor performance of nurse tutors on demonstration of clinical procedures was also assessed to the students and to the nurse tutors themselves. Generally, it was noticed that only $54.3 \%$ (70) $n=129$ of the students from all the nursing colleges agreed that their nurse tutors effectively demonstrates clinical procedures both in class and at the clinical area. Nurse tutor performance of demonstration needs to be appreciated by the students at the clinical area. If the nurse tutor performance on demonstration of clinical procedure is below standard some students can easily identify as they read widely in books about such procedures. The nurse tutors reputation on the students may reduce. Skill acquisition is viewed as complex due to the double demand of developing how to actually perform the skill in question as well as developing a professional understanding of theoretical and social aspects involved in such performance by the nurse tutor [21]. Social aspects are expressed through eye contact, voice, body language, and attention directed towards the "patient". Experiencing procedures from the perspective of the patient gives the students opportunity to reflect on whether their expressions are in accordance with distinctive features of a caring concern. But when the nurse tutor fails to these skills students tend to despise the performance of such nurse tutor.

Another concept under teaching affective performance of the nurse tutors were on the willingness to take responsibility for their own classroom and clinical behavior during teaching. Nurse tutor are supposed to take more responsibility on the clinical and classroom behavior that would lead to student quality learning process. But only $47.3 \%$ (61) $n=129$ of the students throughout the nursing colleges in Malawi agreed that their nurse tutors have a willingness to take their own responsibility during teaching both in class and at the clinical area. This is a very awkward situation as nurse tutors dedication must be shown during teaching both in class and at the clinical area. In another study, results showed that the main factors leading to a lack of responsibility on clinical teaching by educational staff include lack of control and a sense of conflict, stress and anxiety in the ward-teaching situation, lack of peer support and an inability to plan ahead for such work. The most pervasive feature which emerged, however, was the felt lack of available time for clinical work in comparison to their other duties. This is discussed in terms of role strain. Differences in response between nurse tutors performance in 
the clinical area were studied and showed that all the problems found appear to be greater among the nurse tutor groups. This may be a consequence of a further finding that clinical nurse tutors are more likely to make finer and more frequent distinctions between the aims and problems of ward- and school-based teaching [22].

The teaching performance of nurse tutors on guiding clinical students on resource mobilisation was also looked into during analysis. 56.5\% (73) $n=129$ of the students from different colleges of nursing in Malawi agreed that nurse tutors guide nursing students on resource mobilisation during teaching particularly in the clinical area. This means that both students and nurse tutors are agreeing that the performance of the nurse tutor on resource mobilisation is generally met during teaching both in class and at the clinical area. Resource mobilization is a key in Malawi nursing colleges as nurse tutors teach under critical resource constraints [23]. Nurse educators in Malawi nursing colleges face several challenges. There are insufficient numbers of different resources, particularly in rural or under-served areas of the country. They face large work-loads in the face of increasing student numbers with limited resources. There is inadequate continuing professional development which influences the quality of teaching and clinical accompaniment and supervision of students; lack of orientation or induction programmes for nurse educators in many nursing colleges, insufficient up-skilling in new technologies, lack of a structured strategy for nursing educators to acquire new knowledge and skills; and an exodus of nurse educators due to occupation specific dispensation (OSD) and rural allowance. If nurse tutors are given adequate resources for teaching they cannot quit their prestigious employment and work in the non-governmental organizations.

\section{Conclusion}

This study has shown that an effective cognitive, affective and psychomotor nurse tutor performance requires an adequate funding in the nursing colleges in Malawi. There is a strong need to develop effective teaching strategies that can be conducive in developing countries where equipment is very scarce. Nurse tutor performance is not dependent on tutors alone but the type of students and the administrative accountability.

\section{References}

[1] WHO (2010) Statistical Year Book. Sub-Saharan Region, New York. www.who.int

[2] Carlisle, C., Calman, L. and Ibbotson, T. (2009) Practice-Based Learning: The Role of Practice Education Facilitators in Supporting Mentors. Nurse Education Today, 29, 715-721. http://www.sciencedirect.com/science/article/pii

[3] Waterson, E., Harms, E., Qupe, L., Maritz, J. and Makobe, K. (2006) Strategies to Improve the Performance of Learners in a Nursing College; Part I: Issues Pertaining to Nursing Education. Curationis, 29, 56-65. www.ncbi.nlm.nih.gov/pubmed/16910135

[4] Msiska, G., Smith, P., Fawcett, T. and Munkhondya, T.M. (2015) Where Is the Grade Coming from? Problems and Challenges in Evaluating the Clinical Performance of Nursing Students. Open Journal of Nursing, 5, 470-481.

[5] Mbirimtengerenji, N.D. and Adejumo, O. (2015) Utilization of the Teaching Strategies among Nurse Tutors in Malawi Nursing Colleges. Open Journal of Nursing, 5, 276-294.

http://www.scirp.org/journal/ojnhttp://dx.doi.org/10.4236/ojn.2015.53031

[6] Nurses Council of Malawi (2009) Annual Report on Nursing Education. Lilongwe.

[7] DeLucia, P.R., Ott, T.E. and Palmieri, P.A. (2009) Performance in Nursing. Reviews of Human Factors and Ergonomics, 5, 1-40. http://rev.sagepub.com/content/5/1/1.short

[8] Chilemba, E.B. and Bruce, J.C. (2014) Teaching Styles Used in Malawian BSN Programmes: A Survey of Nurse Educator Preferences. Nurse Education Today, 35, e55-e60. www.elsevier.com/nedt http://dx.doi.org/10.1016/j.nedt.2014.12.015

[9] Grigulis, A.L. (2010) Lives of Malawian Nurses: Stories behind the Statistics. PhD Thesis, Centre for international Health and Development, University College London, London.

[10] Msiska, G., Munkhondya, T.M. and Chilemba, E. (2014) Undergraduate Students' Perceptions of the Role of the Nurse Educator during Clinical Placements in Malawian. Open Journal of Nursing, 4, 836-847. http://dx.doi.org/10.4236/ojn.2014.412089

[11] Richman, S.B. (2010) A Process Model of the Link between Parenting Practices and Academic Behavior. Poster Presented at the Fifth Annual Institute of Education Sciences Research Conference, Washington DC. www.sesp.northwestern.edu/docs/cv/4790916114fa17c0b3b01a.pdf 
[12] Mbirimtengerenji, N.D. and Adejumo, O. (2015) Challenges of Nurse Tutor Utilization of the Teaching Aids. Open Journal of Nursing, 5, 516-527. http://dx.doi.org/10.4236/ojn.2015.55055

[13] Caffrey, M. and Graeme F. (2006) Health Workforce "Innovative Approachesand Promising Practices” Study: Attracting and Retaining Nurse Tutors in Malawi; Capacity; Project USAID Global Health/HIV/AIDS and the Africa Bureau Office of Sustainable. Development, Lilongwe. www.intrahealth.org/

[14] Mbirimtengerenji, N.D. and Adejumo, O. (2015) Challenges of Student and Nurse Tutor Interactions in Malawi Nursing Colleges. IJSR-International Journal of Scientific Research, 4, 2277-8179. http://theglobaljournals.com/ijsr/articles.php?val=NTEwOQ==\&b1=137\&k=35\#sthash.DPp234In.pdf

[15] Polit, D. and Beck, C.T. (2003) Nursing Research: Principals and Methods. Williams Book Company, New York. https://books.google.co.za/books?isbn=0781746256

[16] Tomietto, M., Saiani, L., Palese A., Cunico, L., Cicolini, G., Watson, P. and Saarikoski, M. (2012) Clinical Learning Environment and Supervision plus Nurse Teacher (CLES+T) Scale: Testing the Psychometric Characteristics of the Italian Version. Giornale Italiano di Medicina del Lavoro ed Ergonomia, 34, B27-B80. www.ncbi.nlm.nih.gov/pubmed/23326942

[17] Ministry of Health-MoH (2012) Annual Report on Nurse'S Performance. Capitol Hill, Lilongwe.

[18] Roberto Rivera (2011) Research Ethics Training Curriculum. 2nd Edition, Family Health International, North Carolina. www.fhi360.org

[19] Lamba, S., Rawat, A., Jacob, J., Arya, M., Rawat, J., Chauhan, V. and Panchal, S. (2014) Impact of Teaching Time on Attention and Concentration. IOSR Journal of Nursing and Health Science, 3, 1-4. www.iosrjournals.org

[20] Ministry of Health-MoH (2010) Biannual Conference, Karikuti Hotel, Lilongwe, Malawi Nurses Council of Malawi (NCM). 2007 Annual Report; Progress of Nurses in Development, Lilongwe.

[21] Bjørk, I.T. and Kirkevold, M. (2000) From Simplicity to Complexity: Developing a Model of Practical Skill Performance. Journal of Clinical Nursing, 9, 620-631. http://dx.doi.org/10.1046/j.1365-2702.2000.00328.x

[22] Jones, J.A. (2005) A study of Nurse Tutors' Conceptualization of Their Ward Teaching Role. Journal of Advanced Nursing, 10, 349-360.

[23] Barua, A. (2013) Methods for Decision-Making in Survey Questionnaires Based on Likert Scale. Journal of Asian Scientific Research, 3, 35-38. http://www.aessweb.com/pdf-files/35-38.pdf 